\title{
Mineração, neo-extrativismo e conflitos em Barcarena
}

\section{Mining, neo-extractive and conflicts in Barcarena}

Eunápio Dutra do Carmo - Doutor em Ciências da Educação-PUC/RJ, pós-doutorado no Núcleo de Altos Estudos Amazônicos/UFPA. Professor do Centro de Estudos Superiores do Estado do Pará/CESUPA.

Edna Maria Ramos de Castro - Doutora em Sociologia pela École des Hautes Études en Sciences Sociales/EHESS, França, pós-doutorado no Centre National de la Recherche Scientifique/CNRS, França, Professora do Núcleo de Altos Estudos Amazônicos/UFPA e pesquisadora do CNPq.

Júlio Cezar dos Santos Patrício - Professor do Centro de Estudos Superiores do Estado do Pará/CESUPA, Doutorando do Núcleo de Altos Estudos Amazônicos/NAEA/UFPA. Mestre em Economia pela Universidade da Amazônia/UNAMA.

\section{Resumo}

O lugar de fronteira de recursos pelo qual a Amazônia é concebida no discurso nacional dominante continua a orientar a ação do Estado através de suas políticas de crescimento econômico, bem como agentes empresariais interessados em atividades que chamamos de neo-extrativistas, notadamente de exploração mineral, com uso de tecnologias performances de última geração. Entre marcadores desses processos a violência é uma dimensão comum que preside as relações na sociedade, e com a natureza. Essa violência se produz sob várias formas no território, independente de sua ocupação, impondo processos de desestruturação social, étnica e espacial. Esta linha de interpretação orienta a pesquisa realizada no município de Barcarena, objeto deste artigo, localizado às proximidades de Belém e locus de plantas de mineração e de estrutura portuária-rodoviária de grande porte.

\section{Palavras-chave}

Mineração. Neo-extrativismo. Conflito. Barcarena. Amazônia.

\begin{abstract}
The resource boundary by which the Amazon is envisaged in the dominant national discourse continues to direct Government actions through its economic growth policies, and the business agents, many of them interested in extractive activities specially those concerning mineral, forest and aquatic resource explorations. Among the markers of this process we can point out the violence as a common and absolute dimension that presides relation between humans and these with nature. This violence is reproduced in hampering forms of transformation of territory, regardless of its occupation and processes of social, ethnic and social disruption resulting from business and political expansion that aim empowerment. This line of interpretation has directed research, partially presented in this article, done in the Municipality of Barcarena located near Belém where several mining plants are located, including a large road and port structure.
\end{abstract}

\section{Keywords}

Mining. Neo-extractivism. Conflict. Barcarena. Amazon. 


\section{INTRODUÇÃO}

Ainda vista como fronteira de recursos naturais, a Amazônia experimenta transformações sócio-econômicas importantes e um processo de desestruturação espacial decorrentes da expansão do capital produtivo e das tecnologias invasivas que são adotadas. Associada a tais processos, as políticas nacionais de infraestrutura e logística tem buscado apoiar os empreendimentos que se ressaltam na economia nacional de base exportadora, sobretudo dos setores de extração mineral e de commodities agropecuária, em busca de produtividade e competitividade que potencializam a primarização da economia.

Sob outras concepções de território que se inscrevem na experiência social, grupos sociais e étnicos ocupam de forma diversa, e muitos deles milenariamente, territórios no município de Barcarena, Pará, que agora passam a ter interesse do mercado. Eles resistem às investidas do Estado e de empresas para deixar seus lugares de moradia e trabalho. Efetivamente, nas três últimas décadas, a ocupação do espaço acionada por aqueles agentes econômicos tem provocado um quadro particular de conflitos que se acumulam aos demais não resolvidos, desde a década de 1980, quando vários empreendimentos se instalaram em Barcarena, em áreas ja ocupadas por outras modalidades de uso. Os conflitos recobrem uma gama de atores e objetos, que compõem, simultaneamente, um espaço e tensão, reeditando a história social de ocupação dessa região que se destaca pela resitência política.

Desses confrontos que colocam frente a frente racionalidades e concepções de vida distintas, tem emergido processos novos de mobilidade e territorialidade que reconfiguram os cenários do presente nessa região, e revelam a recomposição do campo político, de conflitos e tensões entre atores econômicos, sociais e institucionais.

Este trabalho se propõe a discutir algumas dimensões da dinâmica socioeconômica do município de Barcarena, no estado do Pará, marcado pela presença de empresas transnacionais de mineração cujos investimentos tem levado à redefinição da posse da terra, e dos recursos, com volumosos investimentos direcionados para a produção de commodities da mineração e siderurgia de baixo valor de agregação industrial, e de infra-estrutura portuária e de transporte. Expõe dados de pesquisa sobre as áreas de mineração e portuária do Distrito Industrial de Barcarena. A análise recobre ainda o que ficou conhecido como áreas do entorno, notadamente ocupadas por comunidades locais. Propõe uma análise transescalar dos sistemas produtivos locais e principais atores sociais e agentes econômicos no atual contexto das dinâmicas socioterritoriais. 
O território, como espaço de relações sociais, reflete a dinâmica dos atores e os contextos socio-econômicos, bem como as instâncias culturais e político-institucionais, pois possui formas-conteúdo que, segundo Santos (1996), correspondem aos fluxos, às funções e aos fixos. Neste sentido, a análise teórica construída para este trabalho considera o debate sobre processos de expansão industrial em áreas de ocupação pré-existentes predominantemente por comunidades locais detentoras de saberes coletivos sobre esse território de floresta e cursos d'água.

Na perspectiva adotada, o fio condutor do estudo é a reatualização dos processos de expansão capitalista, a análise das políticas nacionais (econômicas e de logísticas) em curso no município de Barcarena, privilegiando conceitos como territorialidade, redes e conflitos. O trabalho está estruturado em duas partes. A primeira discute a dinâmica sócio-econômica em curso e, a segunda, aponta as tramas sociais referidas à territorialidades, atores e hierarquias de poder.

\section{1-BARCARENA:CONCENTRAÇÃOEMPRESARIALETERRITÓRIO EM DISPUTA}

O município de Barcarena está localizado a $40 \mathrm{~km}$ de Belém, capital do Pará, na região norte do Brasil, ocupando uma área de $401 \mathrm{~km}^{2}$ e é um município em grande expansão empresarial e de relações mercantis na Amazônia Oriental ${ }^{1}$ (Mapa 1). A posição geográfica estratégica quanto ao acesso marítimo para os Estados Unidos, Ásia e Europa, à proximidade de ocorrências de bauxita e outros minerais, e a estrutura portuária instalada para navios de grande porte, formam um conjunto que facilita as atividades empresariais, potencializando a trajetória recente de Barcarena. Todos esses aspectos se alinham a outras dinâmicas de âmbito nacional e global. Por esse entendimento supera-se a ideia de considerar o município apenas como unidade administrativa. Nosso interesse é problematizá-lo como eixo de uma complexa rede de relações sociais, políticas, técnicas e informacionais circunscritas na dinâmica do sistema capitalista de produção. Por essa razão, a história de Barcarena deve ser entendida na interação local-global, considerando essa nova composição de empresas de mineração, de siderurgias, portuária, e uma quantidade considerável de empresas prestadoras de serviços que conformam um espaço empresarial, de trabalho e de competências relacionadas às esferas da gestão e da técnica.

\footnotetext{
Espaço compreendido como a porção leste da Amazônia Legal, incluindo os Estados do Pará, Amapá, Tocantins e o oeste do Estado do Maranhão.
} 
Mapa 1 - Estado do Pará-Brasil - Provincia mineral
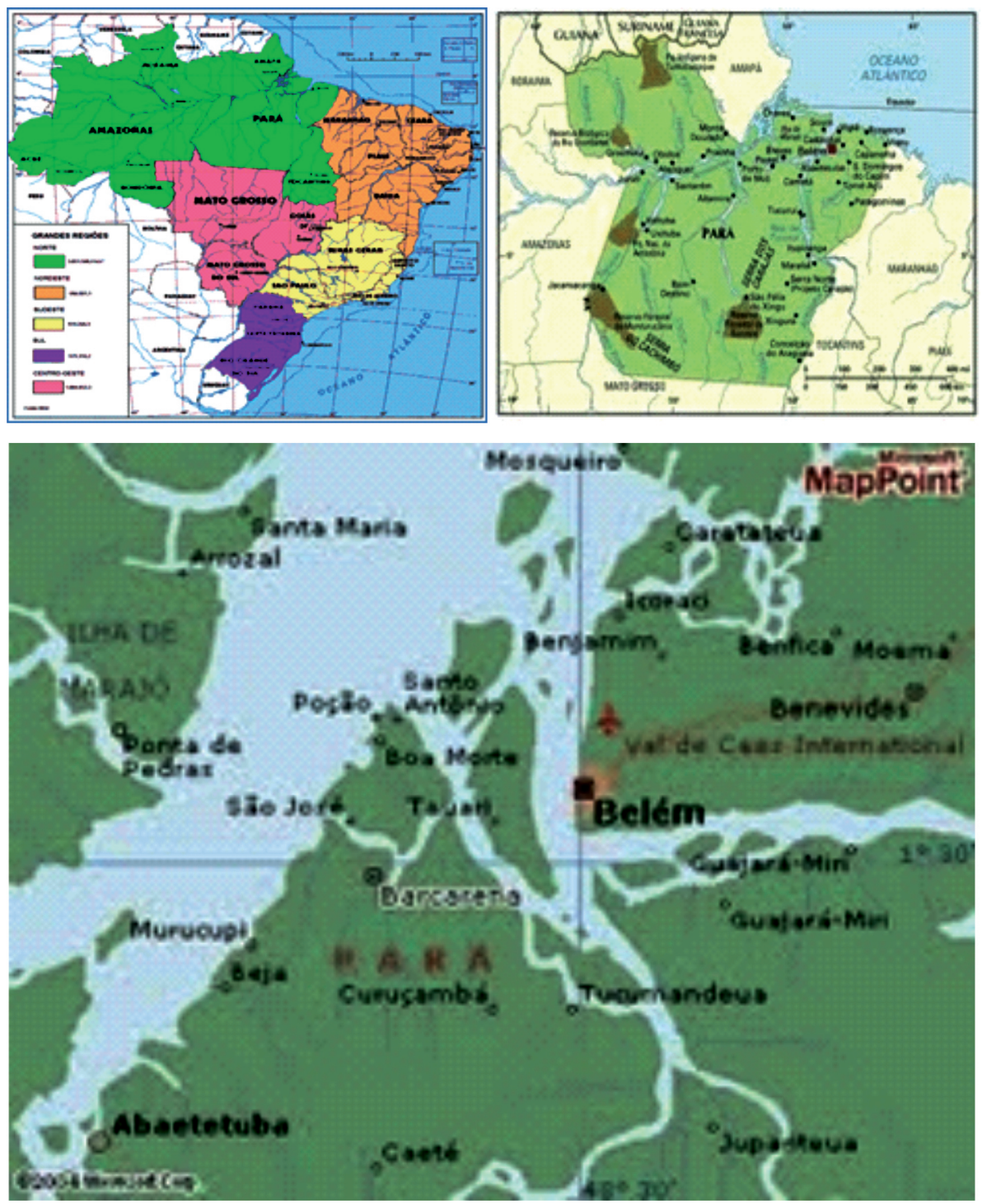

Fonte: Arquivo iconográfico da pesquisa (Mapa adaptado. GEDES, 2010)

Os escritos sobre a história de Barcarena identificam modos de ocupação e usos tradicionais ao longo de rios e floresta que conformam um amplo território, densamente ocupado por povos indígenas que travaram lutas prolongadas com os colonizadores que aportaram no estuário amazônico no correr dos séculos XVI, XVII e XVIII. As marcas da história social e da economia colonial estão gravadas nas ruínas dos antigos engenhos que resistem ao tempo, nas fazendas e 
nas missões religiosas (HAZEU, 2015). Cabe lembrar os núcleos de povoamento, as vilas e cidades erigidas lentamente, referindo-se à posição estratégica ocupada por esse nucleamento, próximo de Belém, e a instalação mais recente das empresas mineradoras nesse mesmo território. Tal posicionamento deu-se no espaço social de populações e comunidades locais que, antes da chegada das grandes empresas, praticavam o aproveitamento dos recursos naturais, com o trabalho familiar - pesca, caça, extrativismo vegetal e animal - a prática dos roçados, como também a extração de frutos típicos da floresta tais como: bacuri, bacuri-pari, cupuaçu, pupunha, cacau, açai, ingá, buriti, uxi, umari, dentre muitos outros, os quais faziam parte da cultura das populações que habitavam aquelas áreas. Esta vida social dos vários segmentos de trabalhadores ribeirinhos, nativos, foi afetada consideravelmente com a implantação das empresas mínerometalúrgicas, que passaram a atuar no município, incluindo-se aí a área do entorno dos empreendimentos minerais onde se localizam as comunidades rurais e étnicas (indígenas e quilombolas) ${ }^{2}$.

O município de Barcarena viveu (e vive) um processo de resistência local/regional ao novo momento industrial, em decorrência da implantação do complexo fábrica-vila-porto referente à racionalidade instrumental das empresas de transformação mineral. A convergência desses interesses explica, de certa forma, a definição e o modelo adotado para o Distrito Industrial de Barcarena.

Esse conjunto de transformações teve seu início com o II Plano Nacional de Desenvolvimento (II PND - 1974-1979), como resposta ao padrão de desenvolvimento do modo de produção capitalista e as estratégicas de reestruturação e de relocalização dos processos/plantas da atividade industrial. As dinâmicas territoriais produzidas pelas estratégias de modernização do mercado, pela reestruturação dos municípios amazônicos, pelos desdobramentos do crescimento urbano, estão diretamente relacionados aos impactos da extração e da transformação mineral presentes na região e à forma de atuação dos vários segmentos sociais que se confrontam em espaços de relações e de contato próprios. Esses grupos têm sofrido as consequências do deslocamento forçado para outras áreas periféricas do município, alterações em seu quadro físico-natural

2 A área do entorno corresponde às diferentes partes da estrutura fábrica-vila-porto do complexo ALBRAS/ALUNORTE, que são: 1) O Distrito Sede - área ribeirinha de ocupação tradicional (...); 2) Vila Nova do Piri - área de capoeira desmatada, e também 'desapropriada' com finalidade de assentamento (...); 3) Laranjal - periferia leste do núcleo urbano, próximo ao rio Murucupi, no trajeto para São Francisco (...) e d) Colônia do Bacuri - assentamento agrícola [com diversos lotes] e e) Vila do Conde - localidade de moradia tradicional de pescadores. 
e, ainda, a poluição propagada por via atmosférica e hidrográfica (COELHO et al., 2005).

Os novos arranjos socioespaciais e as disputas acompanham as dinâmicas sociais emergentes no município de Barcarena. Tal configuração emerge a partir das políticas de desenvolvimento concebidas pelo Governo Federal, na década de 70 e 80, políticas que foram determinantes para este processo de alargamento de fronteira do capital. São resultantes, a implantação de grandes projetos mínero-metalúrgicos e a construção de infraestrutura apropriada para os novos empreendimentos (hidrelétrica, porto, rodovia e vila operária). Os processos econômicos marcados pela eficiência, produtividade e competitividade em marcha desde a década de 90, tem mostrado a integração a mercados e à novas dinâmicas sócio-econômicas. Assim sendo, o padrão capitalista de produção expande-se para áreas de notável potencial de produção, obedecendo também a mudança do sistema produtivo em sua organização e ao fator de mercado instalado. Soma-se a isso o fato decisivo de que, com a globalização (no sentido da expansão das relações de mercado e do avanço tecnológico e informacional), o sistema capitalista conta com novas regulações na competição interempresarial, nas estratégias de mercado, nos padrões de gerenciamento, nas mudanças no mundo do trabalho, questões essas que imprimem ao Estado e à sociedade civil formas de atuação e de disputa com diferentes configurações

Em Barcarena, a área com grande concentração de empresas de extração e beneficiamento de minerais, pertence ao sistema minerário em expansão. As principais empresas de mineração são: a Albras, a Alunorte (aluminio, alumina), a PPSA e a Ymeris (caulim e cobre), com intervenções do capital internacional e nacional, e se colocando como agentes/atores econômicos responsáveis pelas mudanças mais sensíveis no território com suas redes e escalas transacionais de atuação. Destacam-se ainda as empresas de infraestruturas ligadas à produção, armazenamento e circulação de produtos.

Essas grandes empresas mineradoras, espacializadas no Mapa 2, aplicam suas estratégias de ocupação de forma autoritária e acompanhada, em geral, de violência com os grupos que se encontram nos territórios de ocupação tradicional. Elas reeditam novos processos de mobilidade do capital, reconfigurando territórios sob seu controle. A partir dos conflitos sociais e ambientais é possível mapear as diferentes ações de atores sociais na dinâmica local-global com consequências diretas para as mudanças sociais e ambientais. 
Figura 2: Mapa dos Territórios de Mineração no Estado do Para, Brasil.

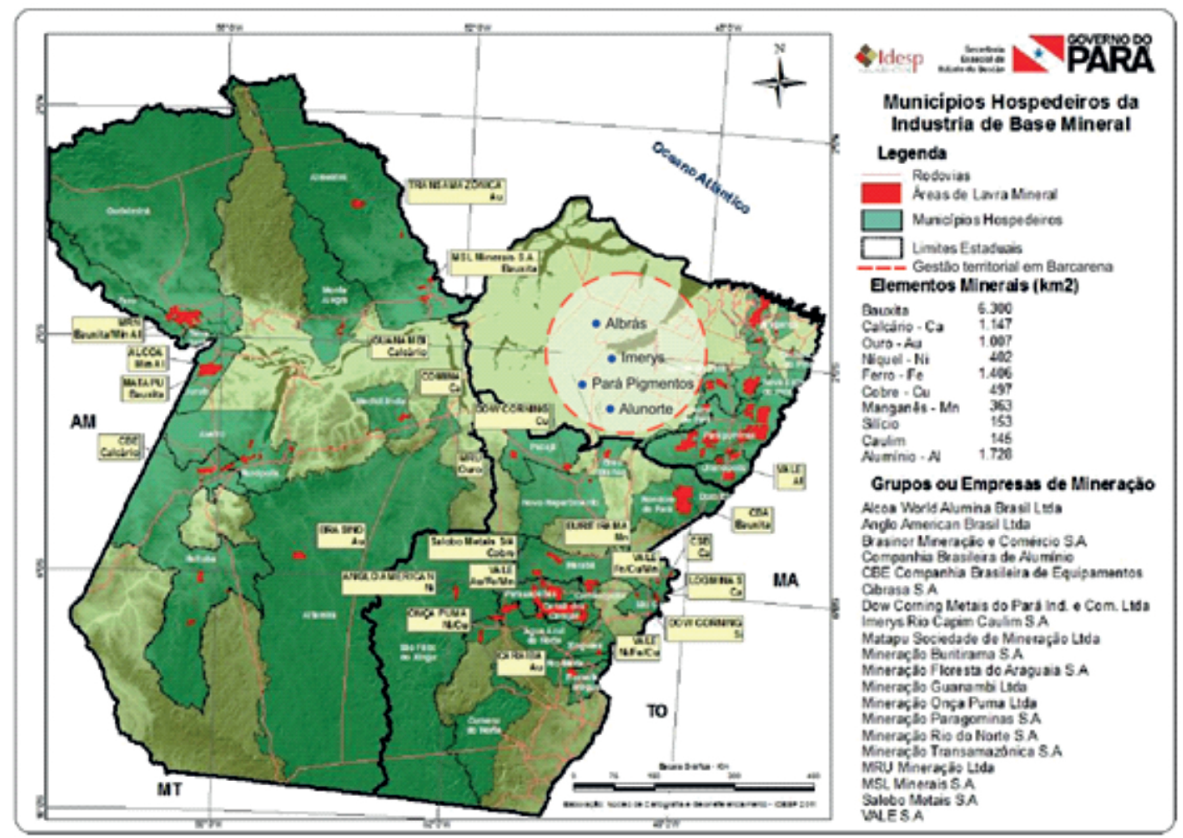

Fonte: Governo do Estado do Pará (2011).

As áreas industrial e urbana (Mapa 3) de certa forma se integram como espaço de interação pelo trabalho de trabalhadores das empresas mães ou de empresas terceirizadas, fornecedoras de serviços ou de bens, ou de dissensão pelos conflitos, que aparecem relacionados à terra, aos recursos e à supressão de formas de trabalho. Além da cidade de Barcarena, assinalamos a Vila dos Cabanos, espaço que foi construído para abrigar os funcionários das empresas e que hoje é ocupado também por outros moradores. As comunidades estudadas e assinaladas nesse mesmo mapa são Curuperé e Nova Vida.

As empresas de mineração e todas as demais que lhes prestam serviços tornam Barcarena um lugar de trabalho. Considerável massa de trabalhadores assalariados, muitos residentes em Belém ou outras cidades próximas à Barcarena, formam um fluxo contínuo de pessoas que se deslocam, a cada dia, por via terrestre ou fluvial, incorporadas ao mercado de trabalho.

A mobilidade do trabalho se cruza com outras formas, não menos dinâmicas, de deslocamento de estruturas empresarias e institucionais. 
Mapa 3 - Territorio Urbano-Rural e localização das empresas de aluminio e mineração

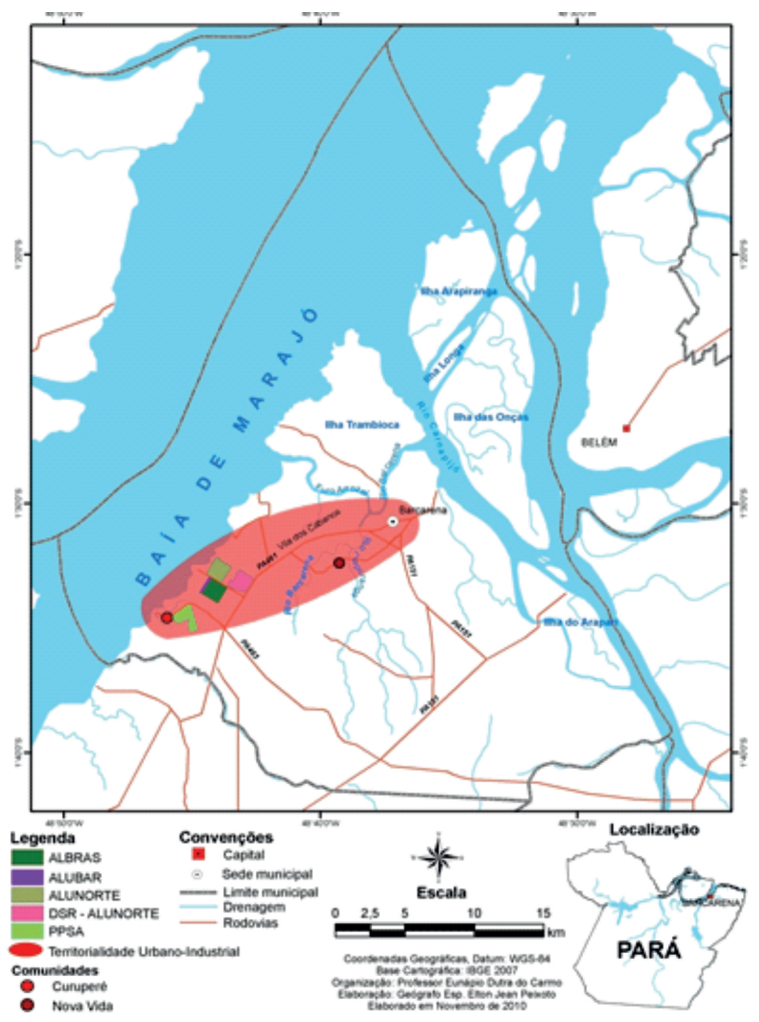

As empresas de mineração receberam grossos incentivos fiscais do poder público (nacional, estadual e municipal) no passado, atualizados por outros dispositivos, e estão, cada vez mais, próximas de ações políticas que estruturam projetos de parceria. A área rural e as ilhas formam o entorno e representam o espaço mais afastados do centro industrial, onde se concentram as comunidades e os grupos sociais tradicionalmente ligados às atividades de pesca, agricultura e extrativismo. Estas comunidades são organizadas com estruturas de política próprias e se mobilizam na defesa de direitos, apesar das dificuldades, contradições e rearranjos nas relações de poder. Essas populações locais, de um modo geral, recebem apoio e assessoria de movimentos sociais e de organizações não-governamentais (ONG'S), que atuam no campo democrático-popular, denunciando e viabilizando alternativas coletivas junto a esse quadro social. Algumas comunidades também mantêm relações com as empresas na medida em que participam de projetos de responsabilidade social, cujo enfoque é nas áreas de educação, cooperativismo e empreendedorismo.

A configuração territorial do município revela o campo de atuação das forças sociais que se territorializaram a partir de interesses coletivos. Este campo 
reforça a representação social do "retalhado" a que se referiu Leonardo do Carmo $^{3}$ ao falar da fragmentação do território tido por eles, no passado, como um território de pertencimento coletivo, com áreas de uso comum e, por isso. entendido como território contínuo.

Segundo os dados do IBGE, a população do município é de 92.567, sendo que 56,11\% deste total habita na zona rural, que é o retrato na Região de Tocantins ${ }^{4}$ (IBGE, 2009), e 43,89\% vive na área urbana. Para a população urbana do município, os equipamentos públicos são melhores, o que pode estar relacionado com a presença das empresas na área industrial. Para ilustrar a força das empresas, que compõem o polo industrial do município: Barcarena colaborou, em 2009, com o volume financeiro de US\$2.278.681.051,00 para a balança comercial do Estado do Pará (PARÁ, 2010b). A receita orçamentária do município, em 2008, foi de R\$160.687.681,70, sendo a maior na região do Tocantins e do próprio Estado (PARÁ, 2010a).

No caso da população rural, a situação é diferente. Os equipamentos públicos são mais escassos, com agravante para as áreas de educação, segurança e transporte. A população vive do trabalho da agricultura com roças de mandioca e leguminosas, da qual produzem farinha e derivados, e do extrativismo do açaí e de outras frutas, produtos esses que são comercializadas na "beira da estrada" e na "feira do centro". Além da produção doméstica e da comercialização, muitas pessoas ocupam-se de atividades sazonais ("bicos"), outros atuam no mercado informal, tendo que se deslocar para os núcleos urbanos, a fim de garantir as vendas dos produtos e serviços.

As forças sociais em disputas "retalham" o município e representam divisão de poder econômico e das condições sociais presentes na região. As disputas são responsáveis por tensões, contradições e conflitos, mas também por negociação, cooptação e mediação. É nessa perspectiva, que podemos entender o processo de industrialização na Amazônia, em que Barcarena é um exemplo emblemático. As comunidades formadas por ribeirinhos e pequenos agricultores veem não apenas a inserção do território na economia globalizada, com a exportação dos produtos da região, mas também assistem e reagem à destruição do seu habitat historicamente construído: o bioma amazônico. A memória das lutas sociais faz parte do capital simbólico e político acionados pelos grupos sociais ou comunidades urbanas e rurais. Esse processo tem revelado a capacidade de organização, mobilização e resistência política, apesar da ocorrência de deslocamentos compulsórios de

Trabalhador local e sindicalista

A região de Tocantins é formada pelos municípios de Abaetetuba, Acará, Baião, Barcarena, Cametá, Iguarapé-Miri, Limoeiro do Ajuru, Mocajuba, Moju, Oeiras do Pará e Tailândia (PARÁ, 2010a). 
comunidades e grupos sociais, seu enfraquecimento e criminalização, e até mesmo o desaparecimento de varias povoações.

A politização como forma de continuar a (r)existir, tem levado esses grupos a utilizarem estratégias como a ampliação da formação, como é o caso da Comunidade Nova Vida que em dez anos viveu dois deslocamentos compulsórios e está na iminência de um terceiro (CARMO, 2010). Nessa, teríamos aí a necessidade de correlação de forças presentes nas comunidades, movimentos sociais, prefeituras, empresas e Estado (representado pela SECTAM e CDI). Para os movimentos sociais e organizações políticas trata-se de um processo de 'retalhamento" do município com suas estratégias e formas de atuação 5 .

No conjunto dessas reflexões, situa-se a história recente do município de Barcarena. Contudo, é preciso considerar que todo fato histórico é sociocultural. Essa perspectiva é central para este trabalho e nos traz para o campo da história social, que coloca o indivíduo, os grupos sociais e as situações por eles protagonizadas como importantes para a compreensão de outra história a partir da realidade local produzida pelos sujeitos sociais em seus cotidianos. Apesar da riqueza dos estudos sobre a dinâmica econômica e as dimensões estruturais das macropolíticas há prevalência da abordagem relacional (indivíduo e grupo) e sociocultural (compreensão dos significados do mundo social) ou ainda desdobra-se para outros campos de registros e formas de operar com a complexa realidade social.

No plano do Estado e das macropolíticas, essas constatações vindas das realidades sociais das comunidades não ganham a mesma importância, ou são, como ocorreu, invisibilizadas por uma escala de observação dominante em que o tempo e o espaço são ditados por questões e aspectos estruturais da economia. Numa outra perspectiva de escala microssocial, acreditamos que as especificidades históricas dos grupos sociais ali existentes, detalhadas em seus universos sociais, organizacionais, culturais e ecológicos, podem colaborar para uma interpretação da realidade sociopolítica e econômica da região, especialmente, por percebê-la no bojo das contradições sociais que são decorrentes de um longo processo histórico.

\footnotetext{
A história da ocupação desses territorios de uso comum alicerça conceitos e projetos de vida que se estendem no tempo, mas que são diversos. Por isso, para os agentes locais - o que chamamos aqui de forma um pouco genérica e, por isso, sem precisar as suas diferenças, distinções e identidades, de "grupos tradicionais", - seus territórios foram, no passado, continuos, e essa continuidade já rompida, está sob ameaça no que lhe resta. A ação de agentes econômicos, muitos deles provenientes do mercado de terras, tem levado a pressões incontáveis de compra de terras, produzindo o que os moradores chamam de "retalhamento", ou fragmentação, com relativo sucesso pelo deslocamentos de uns de suas terras e pressões sobre os que ali ainda resistem.
} 
No conjunto dessa discussão, há duas linhas de reflexão que ajudam a compreender as relações sociais e políticas, no presente, e o controle local x global onde atuam as empresas em Barcerena, que são: 1) novos arranjos espaciais e dinâmicas sociais que emergem, simultaneamente, com o processo de intensificação do neo-extrativismo empresarial da mineração na Amazônia; 2) nova configuração sociopolítica como parte da tríade espaço de extração mineral, área da empresa e periferia (entorno), como espaços que se completam, inclusive com interações conflituosas; por isso, compreende-los, nessa relação, é fundamental à análise.

\section{2 - TERRITORIALIDADES EM CONFLITO E TENSÃO NAS REDES}

O território é "espaço humano, espaço habitado" (SANTOS et al., 1996, p.18) e, com base na funcionalidade existente, ele pode ser espaço local e espaço global, simultaneamente, como afirma o autor ao considerar que o primeiro se refere ao "espaço vivido por todos os vizinhos", e o segundo "habitado por um processo racionalizador e um conteúdo ideológico” (1996, p.18). A nova macrotendência internacional considera os lugares com papéis importantes na definição das estratégias globais (VEIRA e VIEIRA, 2004). Ou ainda todos os estudos feitos na área da antropologia que ressalta o lugar como locus da política, da cultura e da recriação do imaginário e das identidade (ESCOBAR, 2003).

A Amazônia, como fronteira de investimentos internacionais, insere-se no contexto da geoestratégia da economia global. Alguns municípios, como é o caso de Barcarena, atendem à dinâmica dos lugares-globais e são palcos de novas prioridades em infraestrutura, o que implica formação de novas estruturas de poder e redes no território. O entendimento dessa nova lógica, no atual momento da região e de seus municípios, é fundamental, inclusive para compreensão dos resultados. É fundamental o entendimento da interação entre processos locais e dinâmica de mercados globais, conexões lógicas presentes no complexo mercado transnacional. Os resultados desse processo de mobilidade do capital e do trabalho têm sido mostrados, no caso de novas fronteiras do capital, seja pelo aumento do volume da produção madeireira, agropecuária e de mineração, seja pelo mapa de conflitos identificando atores e recursos em disputa, seja pelos graves problemas ambientais, como o desmatamento e a poluição de rios.

Em Barcarena, essa constatação é ainda maior. As razões passam pelos vários registros e comprovadas modificações na paisagem física e humana. Essas modificações são em decorrência do modelo de desenvolvimento adotado pelo Estado nacional, que visa, de forma estruturante, a promoção da região à reorganização econômica global. A utilização do espaço amazônico, nesta 
perspectiva, como estratégia de integração com o lugar-global, via "grandes projetos", principalmente os mínero-industriais e as plantas de hidrelétricas, instalados estrategicamente em unidades produtivas locais. As decisões tomadas no âmbito externo, seja por governantes, seja por corporações internacionais, determinaram a agenda de intervenção local sem a efetiva participação dos atores que construíram uma dinâmica própria de sobrevivência no "lugarlocal", afetando o espaço físico, a vida social, a economia, a cultura e os laços de solidariedade construídos historicamente pela sociedade, gerando outros problemas no tocante ao processo de exclusão social. Essa condição materializase, pois o processo de exclusão social se manifesta territorialmente.

Assim, o alinhamento desta agenda de pesquisa com a complexa rede de transformações nacionais identificadas, por exemplo, com os eixos de integração a partir de obras de infraestrutura interferem no ordenamento territorial brasileiro. O macro planejamento nacional vem estimulando corredores de transporte que modificam consideravelmente a malha territorial brasileira mediante a adoção de programas estratégicos com intenso impacto nas sociedades locais. Os portos são exemplos dessas novas fronteiras de expansão territorial produtiva (ACSELRAD, 2002; CASTRO, 2007; CASTRO, RODRIGUES, HAZEU, ALONSO, 2014).

Também a agenda de pesquisa requer uma reflexão sobre as multiterritorialidades na Amazônia contemporânea, o que exige, uma reflexão articulada entre o macro e micro: "as articulações entre microprocessos, microiniciativas versus macrodecisões nas várias escalas em que se estruturam e se enfrentam os interesses em disputa”, como sugere Brandão (2009, p. 177). Por esta razão, as mudanças estruturais e a ampliação do Porto de Vila do Conde em Barcarena é das mais significativas expressões dessa relação, pois é resultado das novas determinações territoriais do desenvolvimento produtivo nacional e internacional em que o sistema de portos assume uma nova configuração de "fixidez-fluidez do movimento concreto do capital e o uso que este faz do território em suas múltiplas e variadas escalas espaciais” (BRANDÃO, 2009, 167).

Por essas razões, o território vivido, disputado e gestado pelos atores sociais precisa ser visibilizado. Para Santos (1996), o território é uma construção social, resultado da necessidade dos atores sociais envolvidos. Extendemos a reflexão do território na sua dimensão subjetiva, enquanto sentimento de pertencimento, sobretudo por corresponder a um lugar da memória, da

6 O grande projeto é caracterizado para Becker (1995) pelos seguintes aspectos: "1) pela escala gigante da construção da mobilização de capital e mão-de-obra; 2) pelo isolamento, implantado-se geralmente como enclaves, dissociados das forças locais; 3) pela conexão com sistemas econômicos mais amplos, de escala planetária, de que são parte integrante; 4) pela presença de núcleos urbanos espontâneos ao lado do planejado, expressão da segmentação da força de trabalho, qualificada/não-qualificada" (p. 63-64). 
história, marcador de identidades e, seguramente, carregado de simbolismos, representações no imaginário coletivo, na linha de interpretação crítica trazida pela antropologia do desenvolvimento e pelos estudos pós-coloniais (ESCOBAR, 2003; APPADURAI,. 2004)

A constituição do território se dá pela experiência, ação no espaço e pelo trabalho. Essa é a percepção de Raffestin (1993). Na sua concepção, o espaço antecede o território, sendo este último produzido socialmente, apropriado pelo trabalho de um grupo social inscrito num campo de poder. O exercício do poder, em suas muitas dimensões (estado, empresas e sociedade civil), é revelador das instâncias em que ele é exercido. O território é assim apropriação pelos atores sociais e sobre os quais produzem saberes e se utilizam de tecnologias em intensos processos sociais, materiais e imateriais. São processos materiais aqueles vinculados ao controle, dominação político-econômica e os processos imateriais estão relacionados à cultura e à identidade. Esses processos (i)materiais são históricos e ontologicamente compõem as relações sociais de grupos sociais quando usam o espaço. Em síntese, o território é "um espaço criado pelo homem" (CICHOSKI e SAQUET, 2013), quando este se apropria do espaço, ele está constituindo o território. Logo, o território é "uma ficção do espaço apropriada socialmente" (CICHOSKI e SAQUET, 2013).

Outros autores (SAQUET, 2007; HAESBAERT, 2004) tem contribuído no debate com uma visão híbrida dos processos analisados a partir de conceitos como território e gestão territorial. Saquet (2007) sugere a abordagem híbrida e relacional do território, situando seu debate na perspectiva de escalas. Para este autor, o território compõe a interconexão com lugares globais, conformando os espaços econômicos fragmentados. Já Haesbart (2004) vê o território com uma dupla dimensão do poder simbólico: no sentido da dominação (políticoeconômico-disciplinar) e no sentido da apropriação (identidade-afetividade). No encontro deste campo híbrido, a categoria território expressa uma imbricação envolvendo o sentido funcional (utilidade) e o sentido identitário-simbólico (significados e expressividade) conforme Haesbaert (2004), percebido nas práticas sociais e nas territorialidades dos agentes do campo relacional.

A territorialidade contem as dimensões objetivas e subjetivas que se expressam pelas identidades e práticas sociais. Decorre das relações sociais (existenciais e de produção) que se dão na dinâmica do território. e na ação dos sujeitos. A territorialidade corresponde ao "conjunto das relações mantidas pelo homem; como ele pertence a uma sociedade, com exterioridade e alteridade através de mediadores ou instrumentos", conforme Raffestin (1993, p. 267) vivida em todas as suas dimensões. 
O que se verifica é um movimento de confronto que coloca em choque concepções diferentes sobre o espaço e as territorialidades, envolvendo empresas transnacionais e comunidades sociais, onde se questiona a intervenção do poder econômico e a consciência dos membros das comunidades que reagem. A contraposição que se estabelece frente à racionalidade econômica excludente e promotora de desigualdade social diz respeito à pluralidade do poder espacialmente localizado (FISCHER, 2002). Descortina o debate sobre desenvolvimento e como os atores sociais podem questioná-lo, impondo reações pelo avesso daquela racionalidade. É o embate das forças sociais, suas alianças e conflitos que norteia a matriz de possibilidades políticas e outros programas de desenvolvimento local. São tramas que credenciam Fischer (2002) e, principalmente, Almeida (1996) e Acerald (1996) a vislumbrarem novas dinâmicas na atuação das organizações e dos movimentos sociais.

O território de Barcarena sempre experimentou muitas mudanças. Porém, nos últimos cinco anos, o município vem vivendo intensos processos que afetam as lógicas das relações políticas, sociais, econômicas e culturais. Esses processos estão associados com as formas de ocupação e de apropriação do território, tendo como maior foco garantir a capacidade produtiva e logística em detrimento das políticas sociais e equipamentos urbanos favoráveis ao bem estar da população. O caráter dessas intervenções em Barcarena não é homogêneo. Ele diferencia-se considerando as dimensões tempo-espaço na economia globalizada que pode ser explicada pela ação dos atores sociais na fronteira, formando diversos cenários de interesses em disputa que revelam os projetos dos atores e suas tramas: "O que está em jogo não é o território em si, espaço físico apropriado ou pretendido, mas a territorialidade enquanto exercício de um domínio que se realiza ou se projeta pelas relações políticas historicizadas" (CASTRO, 2007, p. 37 ).

O debate acerca dos temas territorialidades, redes e conflitos é impotante à compreensão da transescalaridade dos sistemas produtivos locais em Barcarena. A transescalaridade colabora para a compreensão das novas dinâmicas do município de Barcarena e que delineiam territorialidades bem mais complexas e em escalas global, nacional regional e local, redefinindo o território-rede. Portanto, os múltiplos territórios de Barcarena, protagonizados pelos seus diversos atores sociais, expressam as diferentes forças de apropriação que se atualizam à medida em que novas possibilidades de uso são estratégicos para os projetos e atividades desses agentes sociais. Nesta direção, a transescalaridade será entendida como campo de ação político-estratégico em que as ações de concepção e intervenção no funcionamento do território são desenvolvidas. O sistema territorial corresponde ao campo de relações de envolvimento do Estado, empresas/organizações e 
indivíduos. São dessas relações com as dinâmicas político-econômicas que se formam malhas, nós e redes, assim compreendidos: a) malhas - representam conexões, ligações heterogêneas entre diferentes atores sociais; b) nós - são pontos de encontro de relações sociais, sendo interdependentes, podendo estabelecer comunicação entre si e; c) redes - representam ligação entre dois ou mais atores sociais; “(...) a rede faz e desfaz as prisões do espaço, tornado território: tanto libera como aprisiona” (RAFFESTEIN, 1993, p. 204).

Nesse sentido, os agentes econômicos disputam o espaço, dividindo-o. Criam os nós e articulam as redes, cabendo portanto redefinir outras formas de coesão nos territórios, ou sistemas de poder, os quais passam a ser dispostos de maneira hierárquica, favorecendo o controle sobre o material a ser distribuído, demarcando os campos de ações (de poder) nas relações socioterritoriais. As redes dão suporte para o controle do/no espaço mediante a mobilização, circulação e comunicação protagonizadas pelos atores sociais, desenhando suas territorialidades e, portanto, tem o poder como matéria.

Como principal ator de intervenção no territorio, o Estado acaba pro produzir fragmentações no espaço para melhor controlar e dominar processos, fazendo destas ações suas estratégias de gestão territorial, como tem sido amplamente analisado casos sobre a relação entre Estado e povos indígenas, a exemplo dos povos do Xingu (VIVEIROS DE CASTRO, ANDRADE, 1988). No entanto, outras organizações produzem territórios e processos de intervenção, criando suas próprias malhas. Sabemos por vasta literatura que os atores sociais produzem o território, partindo da experiência social, vivida no tempo-espaço. Há, portanto, um 'processo' de produção do território particular a cada experiência, por isso, são diversos na sua essência. Neste sentido, o Estado, as empresas e as demais organizações da sociedade civil se apropriam do espaço, territorializandose, e se apropriando mediante a implantação de malhas, nós e redes, recortando o território, ligando-o com outras escalas. Assim, são produzidos fragmentações desigualdades, conflitos, sobreposições no território-rede, emfim, territórios em disputa permanente pelas forças sociais.

Daí porque território é concebido como manifestação de poder de atores sociais e as redes são um instrumento político-econômico e institucional deste processo. Logo, é fundamental compreender o poder no território para além do estatal, problematizando a existência e a emergência de outros poderes, ampliando a concepção do território para uma sociedade complexa e diversa. A leitura deste território do ponto de vista do Estado pressupõe ação sobre o espaço com aparato jurídico que legitima a ação do poder público. Sendo assim, a "gestão é o exercício do poder estatal sobre o território" (AZEVEDO JUNIOR, SILVA, 2011, p. 
$131)^{7}$ no campo da dominação/apropriação do espaço por um poder políticoeconômico. Importante também destacar o caráter da mediação neste campo, como possibilidade de atuação do Estado em sua interação com os demais poderes no território, inclusive em regiões interculturais e diversas como a Amazônia, onde se apresentam intermediações, provocadas pela presença de novos atores que acabam implicando o território de acordo com seus interesses globais-locais.

Os territórios de mineração estão associados aos megaprojetos de intervenção federal, a exemplo os Planos de Aceleração do Crescimento (PAC I e II), de caráter infraestrutural para integrar competitivamente a região aos mercados globais e aumenta os níveis de investimentos e de confiança produtiva do país. Castro (2012) chama atenção para o fato de que os incentivos na malha de transporte, energia e comunicação estão relacionados diretamente com a política de commodities, portanto, ainda centrada no crescimento econômico. Neste sentido, Barcarena é uma cidade estratégica no contexto político de dominação/ apropriação. Os territórios de mineração ocupam funções políticas e econômicas que inserem o município no rol de lugares-globais com condições necessárias para a expansão dos negócios internacionais com rebatimentos para a indústria nacional (CASTRO, 2015).

O desencadeamento de estratégias de racionalidade produtiva aliado a mecanismos políticos de modernização nas relações públicas e privadas vem se ampliando e se atualizando, simultaneamente, com as mudanças nos cenários macroeconômicos, principalmente considerando as estratégias de expansão e eficiência produtiva das mineradoras no município. Somado a isso, estão os seguintes acontecimentos: instalação de novas empresas, revisão das agendas ambientais, desapropriação de áreas, remanejamento de famílias, mudanças das forças políticas, resistência, desaparecimento e formação de comunidades e atuação de novas organizações da sociedade civil. Ao interior das usinas, inúmeras greves tem acompanhado as lutas por melhores salários, contra os efeitos da restruturação produtiva sobre o trabalhado e sobretudo quanto às formas de precarização via redução de postos de trabalho nas empresas-mães e transferência para empresas subcontratadas. Certamente são práticas correntes desde o final do século XX com efeito sobre todo o regime salarial, no mundo do trabalho, como assinalam Ramalho \& Carneiro, 2013).

O município se reestruturou e foram introduzidas novas atividades econômicas. Houve uma crescente urbanização combinada com um

Azevedo Junior e Silva (2011) desenvolvem importante estudo sobre a utilização das categorias gestão e gestão territorial por parte dos autores dos artigos da Revista Brasileira de Geografia. Além da sistematização das principais publicações, o estudo consegue apontar as compreensões em curso sobre os temas. 
extraordinário boom demográfico transformando o sistema territorial do município e redesenhando as posições estratégicas dos atores locais. Com isso, podemos considerar que há novos elementos que incidem na gestão territorial. Não obstante a CODEBAR (Companhia de Desenvolvimento de Barcarena), continuando com seu papel de controle territorial no município, faz-se mister notar que há novas condições estruturantes institucionais e territoriais de regulação social

A gestão territorial inscreve-se num campo de poder, redes e conflitos e se materializa nas relações institucionais e cotidianas ligadas às dinâmicas políticas, econômicas e culturais que envolvem diversos atores sociais que protagonizam formas de acesso, disputas e negociações. Neste sentido, é pela apropriação econômica (material) e cultural (imaterial) que ocorre a territorialização, logo a gestão territorial deve considerar a complexidade dos interesses e o caráter de espaço econômico fragmentado que se intensificou em Barcarena como campo de produção e de poder, portanto de conflitos em razão das formas de apropriação local-global a que está submetida. Essa dinâmica compreende também o fortalecimento das redes e, como analisa Raffestein (1993), elas têm o inacabamento como característica. É do inacabado que a rede "tira sua força no espaço e no tempo: adapta-se às variações do espaço e às mudanças que advêm do tempo" (RAFFESTIN, 1993, p. 204). Guardando as devidas diferenças entre as óticas de análise dos autores, em Santos e Silveira (2004) aparece a noção de dialética do território como novos recortes no território engendrados pelos processos geopolíticos e econômicos da globalização, pois se trata de articulados sistema de fluxos, de circulação e produção em processos de transformação permanente. O resgate de ambos (RAFFESTEIN, 1993; SANTOS e SILVEIRA, 2004) quer situar Barcarena como território inacabado e passando por intensas transformações contemporâneas no tempo-espaço da economia global, cujas dimensões são analisadas na perspectiva das novas reestruturações produtivas e territoriais em curso.

Esta apropriação territorial de Barcarena é marcada pela expansão da economia mineral extrativista, pela ideologia de modernização e pelos mecanismos de integração nacional e internacional, transformando socioespacialmente o município em decorrência do sistema de produção econômica adotado, da mudança do padrão demográfico e forma de uso/ocupação do território. Neste sentido, a gestão territorial foi orientada para a exploração econômica do espaço, a fim de atender aos diversos interesses envolvidos e à lógica político-institucional e financeira de transformar Barcarena em fronteira de acumulação de capital mineral.

Os novos acontecimentos em Barcarena são resultantes da interface entre poder, redes e conflitos e revelam processos acelerados de transformação 
que demandam uma nova agenda de discussão, sobre a qual estacamos alguns pontos relevantes: 1 - O licenciamento ambiental passa também a ser uma prerrogativa do poder local (Prefeitura), e sofre, no âmbito nacional, processos de flexibilização; 2 - Análise e balanços sobre a política estadual do Programa Município Verde, ao qual o municipio de Barcarena aderiu; 3- Foi pré-instalado o Fórum de Diálogo Intersetorial de Barcarena com a pré-adesão de empresas mineradoras, prefeitura e comunidades com objetivo de construir uma agenda de desenvolvimento local; 4 - Processos em curso de capacitação dos gestores públicos desenvolvida em parceria entre a Prefeitura e as empresas mineradoras; 5- Acompanhar a liberação e a execução dos recursos calculados em torno de 160 bilhões de reais programados para o município e oriundo do setor público e da iniciativa privada; 6 - Discutir e analisar os procedimentos da Secretaria de Ordenamento Territorial criada recentemente com o objetivo de acompanhar o processo de transformação no município.

Essa agenda certamente prioritária, em função dos impactos sociais e ambientais da mineração produzidos pela aceleração da economia no espaço local, não elimina outras agendas de pesquisa $^{8}$ e o trabalho de controle social e vigilância por parte da sociedade organizada em movimentos sociais. Os desastres da mineração no estado do Pará e, mais em particular, no municipio de Barcarena, conforme amplamente demonstrado por pesquisas e pela observação local empreendida pelos movimentos sociais que ali atuam, são notórias e se acumulam sem a devida visibilidade da sociedade e do poder público.

\section{CONSIDERAÇÕES FINAIS}

As pesquisas realizadas sobre mineração no Pará tem mostrado pertinência em relação às denúncias sobre os desastres ambientais e sociais e às tensões relacionadas à luta pela terra. A história de Barcarena tem sido marcada pelas disputas de agentes de fora que preiteiam a exploração de recursos minerais e florestais, e as comunidades ali instaladas em tempos diversos. No bojo desta resistência, emergem territorialidades, alteram-se grupos e as formas de mando no espaço local, forjam-se o poder local, suas matizes e produções, estabelecemse jogos e acertos local-local e global-local, ricos em projetos de mobilização. A intensificação da dinâmica territorial na direção de conflitos socioambientais e disputas pelo território fizeram com que os grupos sociais em Barcarena reconstituíssem seus saberes para se mobilizarem, e resistirem, diante do que eles consideram um quadro de desestruturação social e ambiental e da real possibilidade de dispersão e extinção de suas comunidades. Mas fizeram também

8 Ver resultados de pesquisa produzido pelo grupo de Pesquisa Estado, Trabalho, Territorio e Mercados Globalizados (GETTAM), e Anais do SILAT 2015, NAEA/UFPA. 
que os agentes econômicos sofisticassem e ampliassem seu domínio de atuação no município com a infraestrutura e novos modelos de gestão.

O encontro desses agentes (empresas e comunidades), no município, é marcado pelo contato entre culturas diferentes que revelam, de um lado, os valores culturais etnocêntricos (ideologia da modernização) de empresas transacionais e, de outro lado, os valores culturais dos grupos locais. O encontro dessas diferentes culturas não ressalta apenas dimensões socioprodutivas, mas especialmente, as representações simbólicas do que é produzido pelas relações concretas de contato. Certamente, revela também o jogo das relações de poder e de redes políticas que integram esta dinâmica territorial sob o qual se comunicam e se expressam códigos construídos coletivamente. Isso mostra que o território é convenção e confrontação e que ele se movimenta e se fixa. Essa sua constituição é materializada nas relações sociais que se somam, complementarmente, às dimensões imateriais do território (dimensões de poder e da cultura). A situação social e histórica do encontro de diferentes culturas provoca a produção de significados e representações e a mediação cultural tem a tarefa de compreendêlos na cena de novas territorialidades e de movimento de confronto e convergência de interesses em situação.

Mesmo diante de tantos obstáculos, estudar as relações de poder têm trazido contribuições significativas para entender o presente, no sentido de ser possível catalogar as experiências e as iniciativas favoráveis ao debate das condições concretas de desenvolvimento para a região amazônica. A sistematização das experiências de diminuição dos altos índices de exclusão social nesta região de fronteira produtiva e a formação de trajetórias de mobilidade decorre também da instalação de equipamentos do sistema logístico, como a estrutura portuária em Vila do Conde.

Os indicadores do desenvolvimento estão abaixo das expectativas de uma região com valores de investimento alto, o que denota uma dupla expropriação do capital social e natural do município, seja por parte das empresas mineradoras que deixam os rastros dos desastres sociais e ambientais, seja pelas formas de ação política do poder local, que concede, de forma colonial, a exploração do trabalho através de minimização da remuneração ao trabalho, de pagamento de impostos e de facilidades e negociatas para dar acesso livre à terras e recursos naturais.

Observa-se a ação articulada de grupos sociais organizados por diferentes processos de resistência apesar das fragilidade econômicas e de poder de agenciamento da política. Ressalte-se, porém, as suas lutas micropolíticas em direção ao bem-estar coletivo. São conquistas lentas, mas forjadas nos movimentos de tensão marcados pelos acontecimentos de (des)construção e (des)continuidade vividos intensamente e gestados nos intersticios das lutas das 
comunidades em continuar sendo o que são, como se auto-intitulam "agricultores e pescadores da mata nativa, caboclos da região, gente da Amazônia". O protagonismo, os conflitos e as lições desses grupos sociais são frutos das suas opções e decisões políticas em contextos de deslocamentos. Conhecem, de fato, a realidade e têm identidade territorial com o local. Notamos que as contradições sociais e as iniciativas de diálogo e de colaboração entre atores e setores da sociedade civil organizada (mediadores) abriram oportunidades inéditas para a mobilização de recursos e aquisição de novas competências. No entanto, o processo de transformação social em curso é veloz e gesta contextos políticos e novos desdobramentos sociais que também desafiam as estratégias dos atores e dos agentes econômicos envolvidos no processo.

\section{REFERÊNCIAS}

ACSELRAD, H. Território e Poder: as políticas das escalas. In: FISHER, T. (org). Gestão do Desenvolvimento e Poderes Locais: marcos teóricos e avaliação. Salvador: Casa da Qualidade, 2002.

ALMEIDA, A. W. B. de. Os deslocamentos compulsórios de índios e camponeses e a ideologia do desenvolvimento. MAGALHÃES, S. B., BRITO, R. \& CASTRO, E. Energia na Amazônia. Belém: MPEG/UFPA/UNAMAZ, 1996.

APPADURAI, A. Dimensões culturais da globalização: a modernidade sem peias. Tradução de Telma Costa. Lisboa: Editorial Teorema LDA, 2004.

AZEVEDO JUNIOR, R. S. e SILVA, R. C. da. Os Conceitos de "Gestão" na Revista Brasileira de Geografia entre 1980 e 2005. Revista de Geopolítica, Ponta Grossa - PR, v. $2, \mathrm{n}^{\circ} 1$, p. $129-136$, jan./jun. 2011.

BECKER, B. Redefinindo a Amazônia: o vetor tecno-ecológico. In: CASTRO. I. E. et all (orgs.). Brasil: questões atuais de reorganização do território, Rio de Janeiro: Bertrand Brasil, 1995.

BRANDÃO, C. Desenvolvimento, territórios e escalas espaciais: levar na devida conta as contribuições da economia política e da geografia crítica para construir a abordagem interdisciplinar. In: RIBEIRO, M. T. F. e MILANI, C. R. S. Compreendendo a complexidade socioespacial contemporânea. EDUFBA, Bahia, 2009

BRASIL. Ministério do Planejamento, Orçamento e Gestão. IBGE. Contagem Populacional. Disponível em http://www.ibge.gov.br/popu. Acesso em jan. 2010.

CARMO, E. D. do. O território educa e politiza na(s) Amazônia(s): os processos sócioculturais da Comunidade Nova Vida e as dinâmicas de expansão industrial em Barcarena. Tese de Doutorado - Departamento de Educação/PUC do Rio de Janeiro. Rio de Janeiro, 2010, 226 p.

Informação fornecida por um trabalhador rural em 2012. 
CASTRO, E. M. R. Políticas de ordenamento territorial, desmatamento e dinâmicas de fronteira. Novos Cadernos NAEA, v. 10, n. 2, p. 105-126, dez. 2007

CASTRO, E. M. R. Expansão da fronteira, megaprojetos de infraestrutura e integração sul-americana. Caderno do CRH, Salvador, v. 25, n. 64, p. 45-61, jan./abr. 2012

CASTRO, E.; RODRIGUES, C.; HAZEU, M.; ALONSO, S. Megaprojetos e novos territórios do capital: infraestrutura portuária e de transportes na Amazônia. In: CASTRO, E. \& FIGUEIRED, S. L. Espaço público, campo social e sociedade. Belém, NAEA/ UFPA, 2014.

CASTRO, E. Campo do desenvolvimento, racionalidade, ciência e poder. In: FERNANDES, A. C. LACERDA, N.; PONTUAL, V. Desenvolvimento, planejamento e governança: o debate contemporâneo. Rio de Janeiro, Letra Capital, 2015.

CICHOSKI, P., SAQUET, M. A. Concepções de geografia, espaço e território nos Anais do IV Seminário Estadual de Estudos Territoriais e II Seminário Nacional sobre Múltiplas Territorialidades, 2013.

COELHO, M. C. N. et al. Regiões do entorno dos projetos de extração e transformação mineral na Amazônia Oriental. Novos Cadernos NAEA. Belém: NAEA/UFPA, vol. 8, $\mathrm{n}^{\circ}$ 2, jul-dez, 2005.

ESCOBAR, A. Actores, Redes e Novos Produtores de Conhecimento: os Movimentos Sociais e a Transição Paradigmática nas Ciências, in SANTOS, B. S. (org.), Conhecimento Prudente para uma Vida Decente: Um Discurso Sobre as Ciências Revisitado. Porto: Afrontamento, 2003.

FISCHER,T. Gestão do Desenvolvimento e poderes locais: marcos teóricos e avaliação. Salvador: Casa da Qualidade, 2002.

HAESBAERT, R. O Mito da Desterritorialização: do "Fim dos Territórios" à Multierritorialidade. Rio de Janeiro: Ed. Bertrand Brasil, 2004.

HAZEU, M.T. O não-lugar do outro: Sistemas migratórios e transformações sociais em Barcarena, Programa de Pós-Graduação em Desenvolvimento Sustentável do Trópico Úmido /PPGDSTU -UFPA/NAEA, Belém. Tese de Doutorado, 2015.

FIBGE - Censo Demografico, 2010.

PARA: (di)visões territoriais, perspectivas sociais, econômicas, financeiras e ambientais ocupação e uso do território, federalização territorial e recursos naturais/Lúcia Cristina Andrade (coord.). Belém: IDESP, 2010a.

PARA: Relatório Secretaria de Planejamento, Governo do Estado do Pará. Belém, 2010b RAFFESTIN, C. Por uma Geografia do Poder. São Paulo: Ática, 1993.

RAMALHO, J. R., CARNEIRO, M. S. Ação sindical, contestação política e siderurgia na Amazônia brasileira. Belém, Novos Cadernos NAEA. Vol. 16, n. 1 p. 7-28, jan-jun 2013 
SANTOS, M.; SILVEIRA, M.L. O Brasil: território e sociedade no início do século XXI. 6.ed., Rio de Janeiro: Record, 2004.

SANTOS, M. A natureza do espaço. Técnica e tempo. Razão e emoção. São Paulo: Hucitec, 1996.

SAQUET, M. A. Abordagens e concepções sobre território. São Paulo: Expressão Popular, 2007.

VIEIRA, E. F., VIEIRA, M. M. F. A dialética da pós-modernidade: sociedade em transformação. Rio de Janeiro: FGV, 2004.

VIVEIROS DE CASTRO, E.; ANDRADE, L. Hidrelétricas do Xingu: o Estado contra as sociedades indígenas. In: ANDRADE, L.; SANTOS, L. (Org.) As hidrelétricas do Xingu e os povos indígenas. São Paulo: Comissão Pró-Índio de São Paulo, 1988. 